\title{
EDUCAÇÃO E ECOLOGISMO NO ENFRENTAMENTO DO EGOCENTRISMO MODERNO: O REAPRENDIZADO
}

DA ALTERIDADE*

Andreia Aparecida Marin ${ }^{* *}$ Eduardo Silveira ${ }^{* * *}$

\section{RESUMO}

Já há algum tempo, a educação aliou-se ao pensamento ecológico no intuito de compreender e reorientar a relação entre ser humano e ambiente, porém poucos avanços efetivos resultaram desses esforços. Buscamos aqui evidenciar possíveis causas do distanciamento entre discurso e prática, em dois movimentos históricos que delinearam o pensamento moderno: os desdobramentos da racionalidade tecno-científica e o movimento de antropologização que reforça o princípio da individuação, embasando-nos em reflexões da teoria crítica e da fenomenologia, representadas especialmente por Habermas e Merleau-Ponty. Tratamos ainda do distanciamento do mundo vivido, da perda de sentido da alteridade e dos significados da experiência estética e da educação ecológica na re-ligação do ser humano com a concretude.

Palavras-chave: Educação ecológica. Racionalismo moderno. Alteridade. Experiência estética.

\section{INTRODUÇÃO}

A educação tem convivido há algumas décadas com um campo de reflexões de grande complexidade - o pensamento ecológico - e dele recebeu um desafio nas últimas décadas: o de motivar novas reflexões, novos discursos e posturas pró-ativas a respeito da relação do ser huma-

* Artigo recebido em 24/01/2008 e aprovado em 30/05/2008.

** Professora do Programa de Pós-Graduação em Educação da Universidade Federal do Paraná. E-mail: aamarim@ufpr.br

*** Mestrando do Programa de Pós-Graduação em Educação da Universidade Federal do Paraná E-mail: dúbio@ufpr.br 
no com o ambiente, pelo qual foi denominada educação ecológica ou ambiental. ${ }^{1}$ Não obstante, esse não é um desafio simples e não depende unicamente de caminhos metodológicos adequados: ele precisa partir da clarificação de princípios e da compreensão de seus fundamentos, herdados de uma história das teorias de conhecimento, especialmente do desenvolvimento das ciências humanas, de axiologias e das construções socioambientais dos últimos séculos.

Voltando a esses caminhos históricos, é possível identificar alguns condicionamentos importantes para as dificuldades que vivemos hoje. Inicialmente, encontramos um ranço antropocêntrico permeando toda a histórica do pensamento filosófico, especialmente na cultura ocidental, que se afirma e propaga ainda mais na modernidade clássica, ${ }^{2}$ com o advento da racionalidade científica, a partir do século XVII. Todo o esforço de algumas vertentes ecologistas contemporâneas, como a Ecologia Profunda (NAESs, 1989), a Ética da Terra (LEOPOLD, 1966), e várias outras correntes da ética ambiental, centra-se na denúncia da profunda influência desse racionalismo cientificista, por vezes citado como cartesianismo, nos modelos de relação sociedade-natureza que resultaram os tantos problemas socioambientais enfrentados na atualidade.

Esse racionalismo tecno-científico será alvo de nossas reflexões críticas no presente trabalho, justamente porque ele está na base dos enfrentamentos a que a educação ecológica se coloca. No entanto, ele não é o foco único e nem o principal. Trataremos aqui de compreender sob quais condições o ser humano abre espaço para um discurso fundamentado nessa racionalidade que parece tomar características de invencibilidade. Essas condições parecem se desenhar num momento histórico tão importante quanto a já citada emergência da cientificidade clássica: a antropologização na modernidade do século XIX em diante, com sua conseqüente exacerbação do distanciamento entre interioridadeexterioridade do humano, que, por sua vez, resultará num egocentrismo, num desligamento progressivo do ser-humano de suas concretudes e a perda de sentido da comunicação, da alteridade.

Partindo, portanto, desses dois focos principais - razão tecno-científico-desenvolvimentista e perda de sentido da concretude e da alteridade -, queremos motivar reflexões que sustentem a defesa de uma nova concepção de educação ecológica, passando pelos seguintes aspectos: as condições de modernização dos ambientes vividos e suas conseqüências 
para a perda de sentido da concretude; como desdobramento desse último item, a necessidade de retorno ao mundo vivido, por meio da redescoberta da experiência estética; a forma como essa re-ligação pode motivar o ser humano a superar a reclusão no espaço da interioridade e a reaprender a alteridade; a possível influência desses dois movimentos no desenho de distintas vertentes atuais da ética ambiental. Para tanto, passaremos por uma retomada dos conceitos de ecologia e educação, pelas teorias fenomenológicas sobre o mundo vivido, representadas por MerleauPonty, pelas discussões sobre interioridade-exterioridade, por idéias de autores que tratam a questão à luz da fenomenologia e por teóricos da ética ambiental e da estética.

\section{Os SIGNIFICADOS DO DIÁLOGO ENTRE EDUCAÇÃO E ECOLOGIA}

O termo ecologia, criado há mais de um século (por Ernst Haeckel, em 1869) na designação de um campo de conhecimento científico, ganhou uma diversidade de aplicações discursivas na atualidade, servindo inclusive a propósitos meramente comerciais e propagandísticos. Discutiremos as formas como esse uso representa uma perda evidente de seu sentido fundante, na medida em que é subsumido na racionalidade contra a qual coerentemente deveria ser posto. Isso sinaliza para uma necessária recuperação do seu sentido original, principalmente se vamos partir para um diálogo entre ecologismo e educação.

Definindo-se o termo, comumente diz-se que Ecologia deriva do grego oikos, que significa casa, e logia, estudo, resultando no seguinte sentido: um estudo da casa ou do lugar onde se vive. Poderíamos especular, por conseguinte, que o termo pode referir-se à razão operando em função da compreensão do lugar vivido. Adotaremos, enfim, a interpretação de logia não no sentido do exercício de uma razão imperativa, do estudo com base científica, pelo qual se objetifica o mundo e se apropria o sujeito de tal objeto, mas como compreensão derivada de uma vivência fenomenológica. Dessa forma, a ecologia só é possível a partir de um conhecimento que deriva do mergulho do ser humano na casa, no lugar vivido.

De outro lado, o termo educação remete à condução, vindo do latim educare, por sua vez ligado a educere, em que ducere significa conduzir e ex, fora (ScHÜтZ, 2008). Nesse sentido, educação significa preparar o 
indivíduo para o mundo. De acordo com o dicionário de Durozoi (2005) refere-se ainda a levar o indivíduo a atingir um máximo de humanidade. Tem, portanto, o sentido de transformação e, no caso da educação ecológica, podemos vislumbrar um tal significado pelo qual se trata de conduzir o ser humano às mudanças necessárias na sua relação com o lugar onde vive, com o ambiente e a coletividade. Importante enfatizar que não dissemos diretamente transformação da relação, mas transformação do ser humano para a relação. Essa diferença é fundamental, uma vez que reflete o princípio a partir do qual iniciaremos nossas reflexões. Pensar a educação ecológica é partir do ser humano, não o centrando e isolando-o da concretude, como o faz o movimento antropológico da modernidade, mas questionando justamente o que nele impede essa abertura ao mundo, dificultando a relação que precisa ser transformada.

Nesse sentido, vale ressaltar os recorrentes reducionismos que ocorrem no âmbito dos fundamentos e das práticas da educação ecológica. Tal educação precisa deixar definitivamente de ser confundida com ensino de ciências, da mesma forma como precisa deixar de ser reduzida ao treinamento de comportamentos adequados, por onde arrisca a reproduzir uma pedagogia de cunho moralista que jamais pôde gerar posturas essencialmente éticas. Educar ecologicamente pressupõe a redescoberta do humano em si para então vislumbrá-lo em abertura ao mundo vivido. É a motivação de um difícil exercício constante de interiorização, para auto-reconhecimento e reflexão crítica, e reabertura significativa à alteridade, em que volitivamente ${ }^{3}$ redescobre-se o sentido do ethos e da comunicação. A radicalização em um dos âmbitos pode condená-lo ao egocentrismo e ao individualismo ou a uma alienação teleológica nos sistemas que dominam as concretudes.

Caberia, nesse contexto de reflexões, a questão: qual casa? Os discursos ambientalistas da atualidade têm apresentado referências ao ser humano com termos como "habitante planetário", "da Terra Mãe" ou "de Gaia". Essa localização do lugar, num espaço de dimensões planetárias, se por um lado permite a alusão à idéia de sistêmica e de efeitos globais das ações antrópicas, por outro fala de uma escala na qual o ser humano não pode mais fazer a experiência da concretude, do encontro com o mundo da vida. Nesse sentido, tal discursividade peca por deixar de estimular a compreensão de que a casa é também a parte ínfima desse megaespaço, o mundo da vida que acolhe as ações e interações humanas cotidianas. 
À educação ecológica, portanto, apresenta-se o desafio de conduzir o ser humano a esse encontro com a casa esquecida, o ambiente da vida onde se comunica, interage eticamente e se compromete com o espaço da coletividade. Aqui chegamos a um importante ponto de nossa discussão: a tentativa de elucidar as dificuldades desse movimento, passando à especulação das possíveis causas de tal distanciamento entre humano e mundo vivido.

\section{OS PREJUÍZOS IMPOSTOS PELA RAZÃO TECNO-CIENTÍFICO-DESENVOLVI-} MENTISTA

Já é bastante presente nos discursos ecologistas e no campo da educação ambiental os prejuízos do movimento de racionalização no pensamento da modernidade clássica, que resultou numa concepção de ciência que coloca o ser humano numa posição imperativa diante do mundo e da natureza. A objetificação das coisas retira o humano do mundo, constituindo uma ciência que o aliena de sua própria natureza. Em resposta a esse modelo da razão científica, Merleau-Ponty (1984, p. 85), dirá: "a ciência manipula as coisas e renuncia a habitá-las". Há um esforço evidente nas obras de Merleau-Ponty para a superação de uma certa destituição de significados do mundo vivido operada pelo pensamento científico clássico e por uma filosofia centrada na subjetividade, que destacam o sujeito do objeto.

O mundo da percepção, isto é, o mundo que nos é revelado por nossos sentidos e pela experiência de vida, parece-nos à primeira vista o que melhor conhecemos, já que não são necessários instrumentos nem cálculos para ter acesso a ele e, aparentemente, basta-nos abrir os olhos e nos deixarmos viver para nele penetrar. (MerLeau-PonTy, 2004, p. 1)

Em Fenomenologia da percepção (1999, p. 26), Merleau-Ponty observa que o significado possível do mundo se dá pela percepção que pressupõe a inserção incondicional neste mundo: "construímos a percepção com o percebido [...]. Estamos presos ao mundo e não chegamos a nos destacar dele para passar à consciência do mundo". No cartesianismo e no pensamento clássico, há um intelectualismo a partir do qual a percepção se dá pela organização dos objetos sensíveis, operando assim uma desvalorização do sensível. É a inteligência que cria a definição das 
coisas sensíveis, conferindo ao mundo a significação que ele mesmo não possui. Merleau-Ponty defende a arte e a filosofia como contraposição a esse estado de pensamento, centrando-os na crítica declarada a essa significação do mundo pelas categorias do entendimento.

Se Merleau-Ponty questiona a razão científica pelo distanciamento que provoca entre ser humano e mundo vivido, Habermas, em sua obra Técnica e ciência como ideologia (1968), trata dessa racionalização não só como a constituição de uma lógica das relações sociais, mas também como a base de uma teleologia na qual o ser humano consegue reconhecer-se apenas em função de seu papel no sistema em vigência, comportando-se como um autômato em todas as esferas da vida. Nesse sentido, tal racionalidade acaba por ganhar uma autonomia que fará das relações uma pura conseqüência lógica e da automação da atividade humana uma condição de sua continuidade.

Nas sociedades capitalistas, a influência dessa racionalidade acaba por se transformar num importante instrumento de opressão, cujo principal trunfo e risco está em não ser assim reconhecida. A lógica do modelo de produção e de consumo, que se instaura a partir da racionalidade técnica e do discurso desenvolvimentista, é tão convincente que sufoca as condições de contraposição às suas características opressoras. Os sujeitos mergulhados nessa razão continuam a reconhecer a racionalidade técnica como um processo natural, do qual depende sua sobrevivência, sua qualidade de vida futura e as superações dos graves problemas socioambientais que se revelam na atualidade.

Esta repressão pode desvanecer-se da consciência da população, porque a legitimação da dominação assumiu um novo caráter: a saber, a referência à crescente produtividade e ao crescente domínio da natureza, que também proporcionam aos indivíduos uma vida mais confortável. (Habermas, 1968, p. 47-48)

Se, desse extremo, a razão tecno-científica predispõe o ser humano a buscas da satisfação de necessidades artificiais, de outro o afasta cada vez mais do mundo concreto, uma vez que este passa a ser um lugar estranho. Os espaços onde se desenvolvem as atividades de produção, mecanicamente executadas, aqueles onde se busca entretenimento, reprodutores de hiper-realidades, os que representam não mais que não-lugares ${ }^{4}$ destinados ao exercício do consumo, distanciam cada vez mais o ser humano da sua naturalidade. A comunicação carregada de 
significados culturalmente construídos e dada nas relações corpo-a-corpo dá lugar à virtualidade. $\mathrm{O}$ mundo seu, esse que de fato o atinge todos os dias quando sai de manhã, onde deveria sentir o calor do Sol, enxergar e ouvir as pessoas, identificar-se com elas, preocupar-se com os ruídos exagerados que o invadem, não é mais que um acidente cotidiano. Deu lugar ao mundo hiper-real e ao refúgio que consegue encontrar no espaço de sua interioridade.

A DUALIDADE INTERIORIDADE-EXTERIORIDADE E OS DESENRAIZAMENTOS DA CONCRETUDE

É importante, nesse ponto, apresentarmos um outro momento da história do pensamento ocidental que pode ter influências visíveis para esse destaque do espaço da interioridade do ser humano em detrimento do mergulho na concretude. Nesse contexto, as reflexões de Foucault são bastante úteis quando denunciam um rompimento epistemológico entre a idade clássica e a emergência da modernidade, baseado num movimento de mudança da natureza das empiricidades, estabelecido a partir do ocaso da representação, que constituía o modo de ser do mundo empírico no pensamento clássico; a conseqüente substituição da ordem cronológica clássica pela historicidade, que dará espessura ao ser e permitirá a emergência do transcendental; e, o que aqui nos interessa particularmente, o fato de a transcendentalidade dar novo papel à subjetividade (FouCAULT, 1999, p. 289).

Para Foucault, nos clássicos, o sujeito da representação não tinha visibilidade - "não havia consciência epistemológica do homem como tal" (1999, p. 423) -, enquanto, na modernidade, a própria natureza do saber pressupõe um sujeito que olha para a própria condição de sujeito cognoscente. Tal sujeito será, nas palavras do pensador, um "estranho empírico-trancendental", um em si sempre coexistente com um Outro (1999, p. 439 e 451). Há, por conseqüência, um movimento de antropologização, em que a um em si agrega-se definitivamente um Outro, uma sombra: "o pensamento moderno avança naquela direção em que o outro do homem deve tornar-se o Mesmo que ele" (1999, p. 453).

Tudo se passa, então, como se essa superposição do humano reforçasse uma identidade em si, dando espaço especial para o reconhecimento e cultivo da interioridade. Essa dualidade entre mundo exterior e espaço 
da interioridade tem sido motivo de considerações feitas por vários pensadores. Os fenomenólogos, entre os quais destacamos Merleau-Ponty, foram enfáticos em criticar as concepções de humanidade atrelada a uma alienação da consciência do sujeito na sua interioridade. Nesse sentido, Merleau-Ponty afirma na Fenomenologia da percepção:

A verdade não "habita" apenas o "homem interior", ou, antes, não existe homem interior, o homem está no mundo, é no mundo que ele se conhece. Quando volto a mim a partir do dogmatismo do senso comum ou do dogmatismo da ciência, encontro não um foco de verdade intrínseca, mas um sujeito consagrado ao mundo". (Merleau-Ponty, 1999, p. 6)

O conceito de percepção que deriva dessa diferença entre mundo representado e mundo vivido é evidente: se, para os clássicos, a percepção é tão somente a leitura do concreto e do sensível para serem processados pelo entendimento, em Merleau-Ponty ela ganha um caráter de fluidez sensível que reabilita a vitalidade do mundo percebido. Dessa forma, o movimento evidenciado na transição da concepção clássica para a moderna centra-se no despertar do mundo vivido. É Merleau-Ponty mesmo que resume essa transição a partir de três aspectos centrais: reaprendizado da percepção do mundo vivido, pela superação da crítica aos sentidos e da supremacia do saber objetivo; ressignificação do espaço, não limitado à perspectiva da visão humana, com quem mantemos "relações carnais"; redescoberta das coisas como espelho das condutas humanas, com um estilo de ser marcado pela relação intrínseca com o sujeito (MerLeauPONTY, 2004, p. 29).

Dichtchekenian (1988, p. 39), discutindo a alienação e a solidão, fala de um mundo concreto, que diz respeito a nossas vivências, mas que, por vezes, nos aprece com uma opacidade que nos impede de irmos a seu encontro. Nesse encontro, porém, é que se pode vislumbrar a co-presença do outro e de outros "eus" que com a concretude se comunicam.

A vivência do estar mergulhado no mundo se desdobra, então, na vivência do aí, [...] sou afetado pelo mundo, vivo isso agora, e me experimento vivendo modalidades de proximidade e distância, como apelos marcados pela presença do outro nas circunstâncias. Esse outro-eu que eu almejo, cava constantes abismos na minha inerência às coisas e a mim mesmo. [...] O outro-eu, o ser-com-os-outros me remete novamente para o ser com as coisas... (DichtcheKeniam, 1988, p. 40) 
As considerações da autora estendem-se ainda mais na apresentação de três modos de ser no mundo: o mundo natural, o mundo com os outros e o mundo próprio do eu (1988, p. 41). Nessa última dimensão do ser, o ser humano está desperto e livre, não se prendendo a nada. $\mathrm{Na}$ abertura ao mundo dos fenômenos e da relação com o outro, há, por outro lado, uma exposição que exige aprendizado, assimilação e reconhecimento de nós pelos outros, como se "a afinidade com o mundo tivesse que ser conquistada, como se um exterior forçasse o que se tenta vislumbrar como interior, propriedade". O recolhimento na interioridade, na solidão, manifesta-se nesse conflito e fornece um espaço do ser como si próprio, recluso em uma pseudoliberdade.

Kierkegaard discute essa tensão entre o realizável no plano concreto e a posição estática na interioridade, identificando-a como causa de uma angústia que marca a existência humana. Tal existência se pautaria, em outros termos, na relação conflitante entre uma manifesta exterioridade e uma profunda interioridade, mediada pelos condicionamentos éticos. A dimensão estética fala do sentido das vivências na exterioridade, mas sempre precisa admitir um reconhecimento da identidade do ser vivente, numa síntese de liberdade e necessidade (KIERKEGAARD, 2002).

O ser só, nesse sentido, é aquele que se furta ao reconhecimento da concretude e do outro, se ensimesma numa exclusividade que impede o compartilhamento. Não obstante, ele necessita voltar ao mundo da vida, sem o que não saberá quem é, uma vez que é na experiência da abertura à coletividade que ele consegue reconhecer sua própria existência. Dichtchekenian (1988, p. 43) sintetiza que "é preciso voltar às luzes, ao palco" e ouvir o chamado do outro.

o homem vai-se expondo cada vez mais, e as ameaças tornam-se inevitáveis e vão chegando aos contextos mais íntimos da existência. Mas, ao mesmo tempo, só através delas o ser humano se vai reconhecendo naquilo que é propriamente humano, e só através delas ele é chamado a assumir a individualidade, a reconhecer-se naquilo que faz. (1988, p. 53)

É no espaço da interioridade que a individualidade pode se definir e o indivíduo pode refletir sobre o mundo, onde recorrentemente se reconhecerá. Nesse sentido, a interiorização pode significar um isolamento, um movimento de alienação, uma vez que o refúgio da interioridade nada mais será que uma fuga da concretude, ou uma liberdade comprometida, 
na medida em que oportuniza a reflexividade e a motivação para a ação volitiva e novas experiências estéticas.

Há, portanto, duas facetas do mesmo dualismo interioridade-exterioridade: uma delas reflete o significado do termo individualidade, atrelado à tradição que moldou o pensamento ocidental moderno; outra faz referência a um esforço de auto-reconhecimento que permite a ressignificação da abertura à concretude e à coletividade. Na tentativa de tornar essa divergência mais clara, citamos a reflexão do antropólogo DaMatta (2000, p. 9):

Meu ponto de vista é que esse problema diz respeito a uma passagem da individualização (e da individualidade), que [...] são experiências da condição humana, para o individualismo, que é uma ideologia (um valor ou uma determinação social coercitiva e consciente) central apenas na chamada civilização ocidental.

DaMatta defende que o indivíduo não é, na cultura ocidental, apenas parte integrante do mundo, mas um ser dotado de independência e autonomia. Aponta, nesse contexto, uma clara diferença de sentido entre as sociedades modernas e alguns grupos singulares, como várias comunidades indígenas, onde os rituais de passagem exigem a experiência do isolamento e da individualização: nessas, o exercício da interiorização e da individualidade é uma preparação para a vida coletiva, que permite um "conhecimento novo e diferenciado da sociedade e de si próprio", e um comprometimento com os novos papéis e as suas responsabilidades sociais (2000, p. 14). Isso difere em muito da caracterização que é feita do indivíduo moderno como alguém motivado pela riqueza, pela independência e centrado em si mesmo, imerso na sua subjetividade, condição caracterizada por termos como "autonomia", "privacidade" e "autodesenvolvimento".

Tudo isso revela uma boa distância da concepção moderna de subjetividade, pois o que os ritos de passagem acentuam vai na direção de uma subjetividade interdependente, ao passo que a nossa subjetividade é construída salientando uma interioridade marcante. [...] Em um caso a solidão serve para pensar melhor a sociedade; no outro, ela é a única maneira de pensar. Como resultado, o primeiro caso conduz à interdependência; já o segundo, abre caminho para o englobamento da sociedade pelo indivíduo... (DAMATTA, p. 21) 
Em síntese, se o espaço da interioridade avolumado no movimento de antropologização da modernidade permitiu um necessário olhar do ser humano sobre sua própria natureza, abrindo espaço definitivo à consciência crítica, também possibilitou a constituição de um refúgio singular, oportunizando também uma interioridade egológica. Será preciso, portanto, que a emergência do ser consciente de si não represente a alienação do vivente, superando o efeito mais nítido desse destaque da interioridade: a construção de um reduto de individualidade, que resulta no individualismo expresso nas sociedades modernas.

\section{ESTÉTICA CONTEMPLATIVA E ESTÉTICA VOLITIVA}

Encarnar o sujeito no mundo, dando-lhe condições de superar uma ignorância a seu respeito, é a base do esforço de conciliação entre interioridade e exterioridade, cujo poder mais efetivo está, segundo Merleau-Ponty, na arte. É essa proposta que ele apresenta já nos primeiros parágrafos de Conversas: "um dos méritos da arte [...] é o de fazer-nos redescobrir esse mundo em que vivemos, mas que somos sempre tentados a esquecer" (Merleau-Ponty, 2004, p. 2).

$\mathrm{O}$ erro mais freqüente que se comete quando se faz referência à Estética é remetê-la automaticamente ao campo da apreciação do belo ou da história da arte. Na verdade, a arte ensina essa forma de contato primordial do ser humano com as coisas, antes de qualquer análise que ele possa fazer delas, mas a experiência estética fala da intensidade com que, habitualmente, nos misturamos com o mundo, em todas as esferas da vida.

A percepção, pelo visto acima, pressupõe um sujeito que se relaciona com o espaço como um encarnado, um habitante do espaço "com seu meio familiar". Essa relação, portanto, pressupõe uma materialidade imersa no mundo: o corpo. Tal corpo não é aquele separado definitivamente da mente, característico do pensamento clássico: “o homem não é um espírito $e$ um corpo, mas um espírito com um corpo, que só alcança a verdade das coisas porque seu corpo está como que cravado nelas" (Merleau-Ponty, 2004, p.16-17, grifos do autor).

Em $O$ olho e o espirito, Merleau-Ponty $(1984$, p. 86) enfatiza a necessidade de superação dessa concepção de corpo do pensamento científico: 
Mister se faz que o pensamento da ciência [...] torne a colocar-se num "há" prévio, no lugar, no solo do mundo sensível e do mundo lavrado tais como são em nossa vida, para nosso corpo, não esse corpo possível do qual é lícito sustentar que é uma máquina de informação, mas sim esse corpo atual que digo meu, a sentinela que se posta silenciosamente sob minhas palavras e sob meus atos.

A consciência não pode, nesse contexto, ser apartada da dimensão sensível. O que lhe garante o status de consciência perceptiva encarnada é justamente o corpo, que nos coloca imersos no mundo. O corpo carrega um caráter ambíguo de interioridade, que permite a imanência da consciência e da exterioridade, quando é lugar das sensações, sem se reduzir a qualquer uma dessas suas potencialidades. Ele é, ainda mais, um si que não se dá por transparência e assimilação, mas por inerência àquilo que vê, ou nas palavras declaradas de Merleau-Ponty: "eis o enigma: meu corpo é simultaneamente vidente e visível” (MERLEAU-PonTY, 1984, p. 88).

Os prejuízos advindos da já citada racionalização que acompanha a emersão da modernidade clássica, também se fazem presentes em relação ao corpo, como ente material. É sabido que movimento intelectualista gerou uma dicotomia entre corpo e mente, onde o primeiro passa a ser visto como um acessório através do qual se experimenta as sensações advindas dos fenômenos do mundo para, posteriormente, significá-los e organizá-los dissociativamente na mente, que seria a dimensão superior, onde tais experimentações passariam a ter sentido. Esta concepção teve - e continua tendo - conseqüências desastrosas inclusas no bojo das já discutidas acima. Habermas faz referência a esta mecanização do corpo como resultado da crescente racionalidade técnica:

A evolução técnica ajusta-se ao modelo interpretativo, segundo o qual o gênero humano teria projetado, uma a uma, ao nível dos meios técnicos, as componentes elementares do circulo funcional da ação racional teleológica, que inicialmente radica no organismo humano, e assim ele seria dispensado das funções correspondentes. (HABERMAs, 1968, p. 52)

Nesse contexto, o corpo humano fica submetido a uma divisão autômata, pela qual se enquadra num tipo de ação mecânica a que é submetido, ação funcional numa determinada linha de produção da sociedade. Se alguns têm partes do corpo mecanizadas, outros têm o 
intelecto e outros ainda a sensibilidade. Em sua obra Jogos para atores e não-atores, Boal questiona o fato de não conseguirmos agir legitimamente em determinadas situações justamente por estas imposições que nosso corpo limitado, dicotomizado, sofre:

Mas como podemos esperar que as emoções se manifestem livremente através do corpo [...], se tal instrumento (nosso corpo) está mecanizado, muscularmente automatizado e insensível em $90 \%$ das suas possibilidades? [...] É como se vivêssemos dentro de escafandros musculares: seja qual for a emoção que sentirmos dentro dessa vestimenta, nossa aparência exterior será sempre a do escafandro. (BoAL, 2006 p. 60, grifo do autor)

Este se configura como mais um ponto onde se pode inserir o questionamento sobre o posicionamento do ser humano em relação ao outro e ao mundo em que vive. Como pode o ser humano com seu corpo mecanizado, sem possibilidade de sentir-se plenamente no mundo ao qual está vinculado, esteticamente experenciar toda amplitude de sensações, sentimentos e fenômenos aos quais se integra? Não há como ser pelo mundo afetado, pelas suas mais ínfimas provocações, ou sentir-se nele completamente, sem utilizar todo seu corpo, toda sua capacidade sensível.

A perspectiva de superação desta visão racionalista que limita a corporeidade pressupõe a construção de uma noção de corpo, conforme caracteriza Merleau-Ponty, como ente ambíguo, espelho translúcido, um prolongamento material que age como um potencializador das possibilidades experimentadas. Segundo o autor, "é necessário reencontrar o corpo operante e atual, aquele que não é um pedaço de espaço, um feixe de funções, que é um entrançado de visão e movimento" (MERLEAU-PoNTY apud NóBREGA, 2000, p. 1). Esta concepção pode ser denominada de corporeidade, no sentido que dinamiza a idéia de corpo, não a limita, tornando-a fluída em relação ao mundo, aos fenômenos, permitindo-lhe a experiência estética em sua plenitude de significados. Nesse sentido, Nóbrega (2000, p. 6), apoiando-se em Merleau-Ponty, considera que "corpo e consciência não são causalidades distintas, mas uma unidade expressa pela dinâmica da experiência do corpo em movimento", de forma que tanto o mundo percebido quanto a subjetividade são revelados através da corporeidade. 
O momento de superação surge quando o ser redescobre que possui um corpo que não é uma ferramenta subordinada ao seu estar no mundo, e que sim está em consonância com este estar no mundo, não podendo ser dissociada deste pela consciência. Neste ponto, chega-se ao corpo como consciência ampla, interna e externa, indissociável, um prolongamento que emerge no mundo, ligando-o a nós mesmos: "a experiência do corpo revela um modo de existência profundamente significativo, a vivência" (NóBrega, 2000, p. 5).

Quando o corpo chegar a ser considerado com esta complexidade, torna-se possível o acesso ao outro e ao mundo, a volição, a experienciação estética vivencial, por ser parte do mundo, estar nele e ser por ele afetado sensivelmente, sem limitações. Boal (2005, p. 192) considera que se uma pessoa é capaz de "desmontar" suas próprias estruturas musculares, certamente será capaz de "montar" outras. Em outros termos, se uma pessoa é capaz de desmontar suas próprias estruturas musculares, é capaz de estar em corpo, totalmente imersa no mundo, passível de experimentar sensivelmente todos seus fenômenos. Sobre isso, Thomaz (2007, p. 5), discutindo as considerações de Merleau-Ponty (1999), destaca:

Os gestos do corpo descobrem fontes emocionais, criam espaço expressivo, uma vez que o corpo é eminentemente um espaço expressivo, é nosso meio geral de ter um mundo, se limita aos gestos necessários à conservação da vida, colocando ao nosso redor um mundo biológico, devendo ser comparado não a um objeto físico, mas antes à obra de arte. (Thomaz, 2007, p. 5)

Como também é capaz de estar aberta ao outro, possibilitando, desta maneira, o exercício da alteridade. Thomaz (2007, p. 6), ao analisar um grupo de alunos participantes de uma oficina de teatro, observou que o estímulo da corporeidade permitiu o emergir de "imagens arquetípicas que denotam o espaço social" em que vivem, o que vai de encontro ao corpo como fator de sociabilidade apresentado por Maffesoli: "o corpo engendra comunicação, porque está presente, ocupa espaço, é visto, favorece o tátil. A corporeidade é o ambiente geral no qual os corpos se situam uns em relação aos outros..." (MAFFESOLI, 1996, p. 133). 
A REDESCOBERTA DO CONCRETO NO EXERCíCIO DA ALTERIDADE E AS DIFICULDADES DE SÍNTESE DOS DISCURSOS ÉTICOS ECOLÓGICOS

Sobressai desse caminho reflexivo desenvolvido que a educação que trabalha com a relação do ser humano com o ambiente enfrenta condições bastante complexas na atualidade: ela passa por uma tendência de interiorização do ser humano, que muitas vezes o aliena da realidade, ao mesmo tempo em que enfrenta a dessensibilização do humano e a constituição das hiper-realidades e da ideologia de progresso e consumo que a permeia. $\mathrm{O}$ enfrentamento de tais problemas tem, no entanto, um foco comum: sem trabalhar o ser humano em sua essência, como identidade singular e ser social, mergulhado no mundo da vida, tal educação não é possível. Em outros termos, a educação ecológica, antes de construir os argumentos da preservação para as gerações futuras e do catastrofismo global das ações antrópicas, tem de se colocar a serviço da desconstrução do egocentrismo.

Lévinas (1997, p. 38) fala em favor dessa desconstrução quando apresenta um humano dividido: "por um lado, em uma totalidade de maneira a fazer parte dela, em derivar sua identidade do que o distingue das outras partes com as quais se compromete", e, por outro, em "permanecer fora", em "derivar sua identidade não de seu lugar no todo, mas de si". A ética por ele defendida depende da redescoberta do sentido da alteridade, no momento de vivência no mundo, diante do olhar do outro.

Quintás, ao discutir a importância da experiência estética na formação ética do ser humano, também destaca a necessidade de ressignificação do espaço da interioridade, a partir da descoberta de sentido da convivência: "a verdadeira interioridade do homem não surge na 'solidão vazia' do monólogo sustentado em clima de 'desenraizamento', mas na 'relação dialógica' que corresponde a uma vontade de criar em comum âmbitos de convivência" (QuintÁs, 1992, p. 231, grifos do autor).

$\mathrm{O}$ isolamento no espaço da interioridade retira o ser humano dos âmbitos de vivência onde a alteridade pode se formar, e o distancia do mundo concreto, o que o deixa à mercê do poder dos arranjos teleológicos da sociedade de consumo. O ser humano assim dominado é, nesse sentido, um ser desenraizado, em que até mesmo os lugares e as ações cotidianas deixam de ter sentido: "a reclusão engendra um nicho no qual todos os elos diários perdem a força...” (DAMATTA, 2000, p. 20). 
Em estudos realizados na década de 80 no Centro de Estudos Fenomenológicos de São Paulo, Valentini, ao pesquisar algumas comunidades na periferia de um grande centro urbano, fez uma análise bastante significativa sobre a forma como o exercício da alteridade pode ser o veículo de abertura ao mundo vivido. Ao enfatizar a idéia husserliana de que seria necessário passar da concepção de um eu empírico carregado de estruturas psicologistas para um eu verdadeiro, faz a seguinte consideração:

Os sujeitos membros da comunidade vivem mergulhados no mundo dando um sentido para ele e para as realidades nele vividas: os horizontes do mundo abrem-se para eles. Os sujeitos comprometidos com o mundo percebem o valor das coisas e lutam neste mesmo horizonte. [...] Os sujeitos nascem à medida que se desenvolve a comunicação, ou, em outras palavras, que se desenvolve a comunidade. [...] Temos que atribuir ao ego uma origem comunitária. $\mathrm{O}$ ego nasce na e com a comunidade e, sem ela, não teria sentido falar de individualidade. (VaLENTINI, 1988, p.115, 124 e 129)

É também argumentando a favor do exercício da comunicação e da intersubjetividade como fonte de sentidos para o ser humano na sua relação com o mundo vivido que Habermas (1968) já propunha o agir comunicativo como contraponto da racionalidade tecno-científica.

A ética ecológica deve ter como foco central esse reaprendizado da alteridade. Vemos atualmente o nascimento de várias nominações possíveis para a ética com base ecológica. Autores como Junges (2004) e Pelizzoli (2002) nos apontam várias dessas abordagens: éticas conservacionistas e preservacionistas; antropocentrismo mitigado e biocentrismo; Ética da Terra e Ecologia Profunda; ética socialista, holística e cristã; ética da responsabilidade e da compaixão; ética de base crítica e ecoética etc. Perguntamo-nos, porém, o que está por trás dessa diversificação das éticas possíveis e ousamos especular que elas se configuram na densa evolução do discurso ambiental, que reproduz valores distintos conforme o grupo social que o apregoa, mas que precisam avançar da dimensão da discursividade para o princípio comum que deve justificá-las: a dificuldade de avançar da consciência à prática cotidiana. Tal dificuldade reflete o ser humano fragmentado que aqui discutimos, dividido entre um discurso que compreende e reproduz na dimensão do mundo vivido e 
uma inércia permitida no movimento de interiorização no qual imperam os argumentos individualistas.

Nesse sentido, a ética ecológica efetiva será aquela que reflita uma identidade definitiva entre o ser humano e o mundo da vida, que o motive a reconhecer-se em suas concretudes cotidianas e a responsabilizar-se por elas. Em outros termos, um ser humano que se descubra em casa, um ambiente compartilhado que possibilita sua própria vida e deve logicamente possibilitar a do outro que também a habita. Vale, nesse sentido, mais uma reflexão do intérprete de Husserl:

se cada eu descobre-se em si mesmo na sua realidade, numa segunda fase, descobre que todos os sujeitos de alguma forma são como ele, pela constituição intersubjetiva, um eu único e ativo [...] O Eu vê os outros como sujeitos e o mundo deles e o meu formam o mundo próprio comum [...] Esta associação pessoal que determina o mundo comum é uma influência recíproca que se exercita no plano da consciência, da intencionalidade: as pessoas têm, umas com as outras, uma força motivante [...] A vista intersubjetiva abre os olhos para a realidade... (VALENTINI, 1988 , p. 125,126 e 134)

\section{CONSIDERAÇÕES FINAIS E SIGNIFICADOS PARA EDUCAÇ̃̃O ECOLÓGICA}

O movimento reflexivo que fizemos tinha por intenção acrescentar algo ao diálogo entre educação e ecologia, na atualidade. A linha argumentativa que construímos, nesse sentido, parte da revisão de sentido dos dois termos, no intuito de já configurar uma problematização sobre uma possível redução da complexidade do desafio da educação ecológica.

Na seqüência, tentamos caracterizar esse desafio retomando dois processos importantes que possibilitaram a arquitetura da relação que hoje o ser humano mantém com o ambiente: a razão desenvolvimentista advinda da modernidade clássica e o movimento de interiorização associado ao desenvolvimento antropológico da modernidade. Essa manobra reflexiva foi feita justamente para abrir espaço para a discussão de questões profundamente ligadas a essa relação: o distanciamento do ser humano do mundo vivido; a dessensibilização e as tendências alienantes derivadas desse movimento; a ineficácia dos discursos éticos em provocar mudanças significativas nas práticas cotidianas.

Com essa caracterização, pensamos ter chegado ao nosso objetivo inicial: repensar uma educação que se, por princípio, deveria propor-se 
a construir uma lógica ecocêntrica, no enfrentamento prático do egocentrismo submerge na pura reprodução de uma discursividade que vai ficando caduca antes mesmo de ser experenciada. Nesse sentido, educação ecológica não é o processo de ensino-aprendizagem colocado a serviço de um conteúdo de conhecimento - não é ligação ingênua entre prática pedagógica e disciplina de ecologia, nem tampouco treinamento em comportamentos adequados. Se a educação se propõe a ser ecológica deve aceitar o desafio de motivar a reconstrução da relação do ser humano com o mundo e a coletividade, mesmo que para isso seja necessário o difícil reaprendizado do abrir-se à concretude e à alteridade.

\begin{abstract}
Despite the fact that education has allied itself with ecological thinking in order to understand and refocus the relationship between human beings and the environment, there have been few effective advances for some time now. This article tries to find possible causes for the gap between discourse and practice in two historical movements which outlined modern thought: the unfolding of techno-scientific rationality and the anthropologizing movement of individuation which reinforces the principle of individuality. The thinking of critical theory and phenomenology, represented especially by Habermas and Merleau-Ponty, is used as a basis. The distancing of the world as lived, the loss of sense of otherness and the meanings of aesthetic experience and ecological education in the re-connecting of human beings with concreteness is also dealt with.
\end{abstract}

Keywords: Ecological education. Modern rationalism. Alterity. Aesthetic experience.

\title{
NOTAS
}

1. No presente trabalho, o termo "educação ambiental" será utilizado para se fazer referência a um campo de conhecimento já consolidado, que é assim reconhecido na dimensão da pesquisa e da intervenção onde haja o foco na relação educação, ambiente e sociedade. No entanto, usamos a denominação educação ecológica na maior parte do texto, quando não precisamos nos remeter a esse campo daquela forma reconhecido, mas sim tecer considerações sobre seus fundamentos, uma vez que acreditamos que o termo ecológico dá uma noção distinta e de maior amplitude que o termo ambiental: representa um novo logos centrado na relação do humano com o mundo vivido.

2. Adotamos aqui o termo clássico como determinante do período nascido das correntes filosóficas da Ilustração. Alguns pensadores tratam como mo- 
dernidade tal período, incluindo as filosofias cartesiana e subseqüente. No entanto, adotamos aqui a terminologia "modernidade clássica" ou, puramente, "período clássico", para nos referir ao contexto dos séculos XVII e XVIII e "modernidade" para o século XIX em diante, considerando a pós-modernidade como o esboço de um período histórico ainda não efetivamente instituído. Essa classificação está de acordo com vários pensadores contemporâneos, como Foucault, Merleau-Ponty e Habermas.

3. Derivação do termo volição que significa primariamente, e para os fins buscados em sua utilização neste trabalho, ato pelo qual se determina a vontade.

4. Segundo Augé (1994), a definição de lugar traz implícita uma relação direta com o histórico, com o relacional e com identitário e desta forma o espaço, por não possuir tais características relacionais, deve ser encarado como não-lugar. Podemos exemplifica-los com os espaços dos hipermercados e shopping centers.

\section{REFERÊNCIAS}

AUGÉ, M. Não-lugares: introdução a uma antropologia da supermoderninadade. 4. ed. Campinas, SP: Papirus, 1994.

BOAL, A. Teatro do oprimido: e outras poéticas políticas. 7. ed. Rio de Janeiro: Civilização Brasileira, 2005.

BOAL, A. Jogos para atores e não-atores. 9. ed. Rio de Janeiro: Civilização Brasileira, 2006.

DaMATTA, R. Individualidade e liminaridade: considerações sobre os ritos de passagem e a modernidade. Mana Estudos de Antropologia Social. V.6, n. 1, p. 07-29, abr. 2000.

DICHTCHEKENIAN, M. F. S. F. B. Alienação e solidão: caminho existencial. In: DICHTCHEKENIAN, M. F. S. F. B. Vida e morte: ensaios fenomenológicos. São Paulo: Ed. C.I., 1988. p. 39-54.

DUROZOI, G.; ROUSSEL, A. Dicionário de filosofia. Tradrução de Marina Appenzeller. 5. ed. Campinas, SP: Papirus, 2005.

FOUCAULT, M. As palavras e as coisas: uma arqueologia das ciências humanas. 8. ed. Tradução de Salma T. Muchail. São Paulo: Martins Fontes, 1999.

HABERMAS, J. Técnica e ciência como ideologia. Tradução de Artur Morão. Lisboa: Edições 70, 1968.

JUNGES, J. R. Ética ambiental. São Leopoldo, RS: Unisinos, 2004.

KIERKEGAARD, S. O desespero humano. São Paulo: Martin Claret, 2002. 
LEOPOLD, A. A Sand County Almanac with essays on conservation from Round River. New York: Ballantine Books, 1970.

LÉVINAS, E. Entre nós: ensaios sobre a alteridade. Tradução de Pergentino S. Pivatto. Petrópolis, RJ: Vozes, 1997.

MAFFESOLI, M. No fundo das aparências. Tradução de Bertha Halpern Guravitz. Petrópolis, RJ: Vozes, 1996.

MERLEAU-PONTY, M. Conversas. Tradução de Fábio Landa; Eva Landa. São Paulo: Martins Fontes, 2004. 79p.

MERLEAU-PONTY, M. Fenomenologia da percepção. Tradução de Carlos A. R. Moura. 2. ed. São Paulo: Martins Fontes, 1999. 662p.

MERLEAU-PONTY, M. O olho e o espírito. In: Textos escolhidos. Tradução de Marilena Chauí. São Paulo: Abril Cultural, 1984. p. 86-111. (Col. Os pensadores).

NAESS, A. Ecology, community and lifestyle. Cambridge: Cambridge University Press, 1989.

NÓBREGA, T. Núcleos interpretativos para uma teoria da corporeidade: o corpo em movimento, 2000. Disponível em: <www.anped.org.br/reunioes/23/ textos/1714t.PDF>. Acesso em: 17 jan. 2008.

PELIZZOLI, M. L. Correntes da ética ambiental. Petrópolis, RJ: Vozes, 2002

SCHÜTZ, R. Word histories. Disponível em: <www.sk.com.br/sk-hist.html>. Acesso em: 23 jan. 2008.

THOMAZ, S. B. Teatro na escola: cultura e imagens do corpo no processo educativo, 2007. Disponível em: $<$ www.anped.org.br/reunioes/30ra/grupo_estudos/GE01-3656--Int.pdf >. Acesso em: 17 jan. 2008.

VALENTINI, L. Intersubjetividade popular: enfoque fenomenológico. In: DICHTCHEKENIAN, M.F.S.F.B. Vida e morte: ensaios fenomenológicos. São Paulo: Ed. C.I., 1988. p. 39-54. 